\title{
Quantitative analysis of polyurethane nanocomposites with boehmite structures modified using lactic acid
}

\author{
J. Ryszkowska \\ Warsaw University of Technology, \\ Faculty of Materials Science and Engineering, Woloska, Warsaw, Poland
}

\begin{abstract}
In this paper the results of a quantitative description of polyurethane nanocomposites with boehmite microstructure are reported. These nanocomposites have higher abrasive wear and thermal resistance. Quantitative image analysis of SEM images has been performed in order to describe the microstructure of the polyurethane and its nanocomposites. The dependence between the sizes of the spherulities obtained on brittle fractures of materials and their resistance properties were analysed.
\end{abstract}

Keywords: nanocomposites, polyurethane, boehmite, lactic acid, image analysis.

\section{Introduction}

Machine components made from polyurethane are mainly used in mining [1-4]. Often, they can also have high resistance for abrasive wear and thermal stability $[2,3]$. Components like nano-clays or plate-shaped, for example kaolin, mica and aluminium hydroxides, have been added to the polymeric matrix to obtain required heat resistance, high modulus and some other physical and mechanical properties [5-8]. However, the macroscopic properties of such composites heavily depend on the dispersion of the added particles in the polymer matrix $[7,8]$. In order to improve this dispersion, modified nanofillers are used and special processing routes are employed [8].

This paper presents the application of quantitative image analysis to the description of morphological properties of boehmite modified using lactic acid and its nanocomposites. Fracture surface images of nanocomposites were 
obtained using a high-resolution electron microscopy technique. Quantitative analysis of the images, obtained with that technique, allowed us to explain the mechanism of changes of mechanical and thermal properties of polyurethane nanocomposites, as well as allowed us to determine the relationships between the structure characteristics and the properties of examined materials. Hardness, abrasive wear, glass transition temperature and thermal stability of polyurethane nanocomposites were investigated.

\section{Materials and methods}

Boehmite $\left(\mathrm{Al}_{2} \mathrm{O}_{3}\right.$ content $76 \mathrm{wt} \%$, specific surface: $220 \mathrm{~m}^{2} / \mathrm{g}$, particle size $10-100 \mu \mathrm{m})$ was purchased from CONDEA-Vista, Catapal D Alumina. Lactic acid was supplied from Aldrich. Boehmite was modified by reaction with lactic acid for 15 hours [9]. Unmodified and lactic acid modified boehmites were used.

Components used for PUR synthesis were: poly(ethylene adipate) (PEA) 2000 Da Alfaster T-620 (Alfa Systems), 4,4'diphenylmethane diisocyanate (MDI) Isonate M 125 (Dow Chemical), glycol (G1) and glycerin (G2) (POCH).

Polyurethanes with PEA:MDI:G1:G2 molar ratio 6:9:2:1 were synthesized. The modified and unmodified boehmite were added to PUR matrix in 0.5 and 3.5 $\mathrm{wt} \%$. All the samples were synthesized by a one-step method of in situ polymerization. Samples were formed by casting. The curing reaction was performed at a temperature of $120^{\circ} \mathrm{C}$ for 16 hours.

Analysis of nanofillers was performed with Scanning Electron Microscopy SEM LEO 1530 and Transmission Electron Microscopy Jeol Jem 3010. The morphology of polyurethanes and nanocomposites was characterized by high resolution scanning electron microscopy (HRSEM) LEO 1530. Brittle fracture samples for SEM study were obtained by cryogenically fracturing ca. $2 \mathrm{~mm}$ thick polymers samples (previously frozen in liquid nitrogen). The fracture surfaces were coated with carbon films of a total thickness of $20 \mathrm{~nm}$ by sputtering. A differential scanning calorimeter (DSC), TA Instruments Model Q 1000 was used for thermal analysis. The weight of the samples was about $10 \mathrm{mg}$. Samples were heated from -100 to $200^{\circ} \mathrm{C}$ at the rate of $10^{\circ} \mathrm{C} \mathrm{min}^{-1}$ in nitrogen atmosphere. Thermogravimetric analysis (TGA) was carried out with a TA Instrument TGA Q 500 thermogravimetric analyser. The samples weight was $10-12 \mathrm{mg}$. The work was performed at temperatures beginning from room temperature to $600^{\circ} \mathrm{C}$ at a heating rate of $10^{\circ} \mathrm{C} \mathrm{min}{ }^{-1}$ in nitrogen atmosphere. Tensile tests were performed using an Instron 1115. The samples were elongated at the rate of $500 \mathrm{~mm} / \mathrm{min}$ according to ISO 527 . Hardness was measured using an indentation hardness tester according to ASTM D2240-75, abrasive wear according to ISO 4649 .

\section{Results and discussion}

Boehmite modified with lactic acid was introduced into the polyurethane matrix. Images of boehmite before and after the modification are shown in Fig.1. 


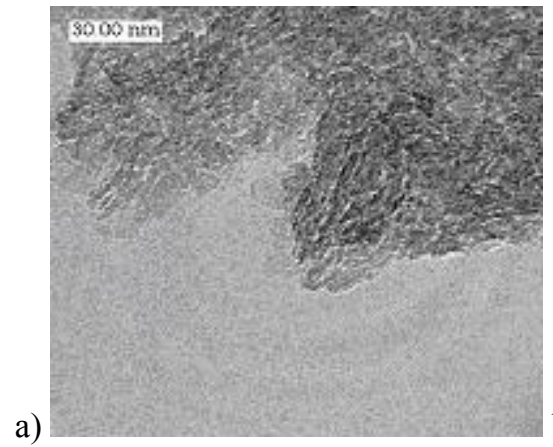

b)

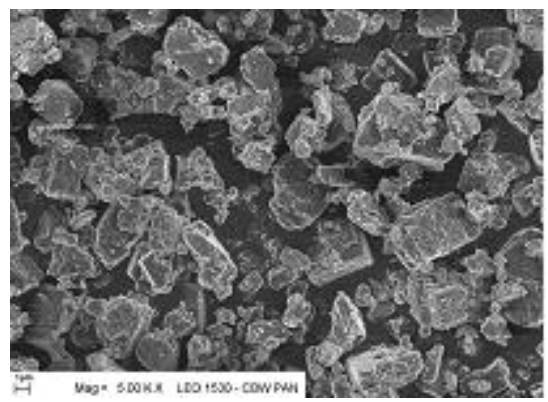

Figure 1: $\quad$ Images of boehmite modified by lactic acid: a) TEM, b) SEM.

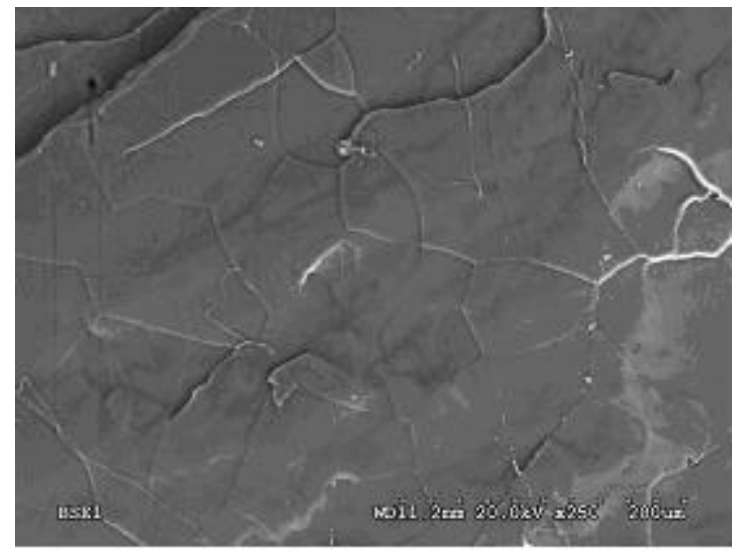

Figure 2: $\quad$ SEM images of cryogenically fractured surfaces of polyurethane.

Modification boehmite creates aggregates in cubic form built from tiles $5 \mathrm{~nm}$ thick, its specific surface is $13.6 \mathrm{~m}^{2} / \mathrm{g}$ and helium density $1.46 \mathrm{~g} / \mathrm{cm}^{3}$. Images of fracture surface of the polyurethane matrix are presented in Fig 2.

In Fig 2 spherulite structures can be seen, obtained on the images of brittle fractures of polyurethanes [10]. Such structures were also observed in polyurethanes researched by $\mathrm{Li}$ et al [11] and Briber and Thomas [12]. One type of spherulite structure observed by Briber did not show optical nonbirefringence. Observations of nanocomposite with boehmite brittle fractures were also performed and are shown in Fig. 3(a) and (b).

Filler gain is evenly distributed in the matrix. The fracture images of nanocomposites resembling spherulite are visible. Their boundaries are not, however, as clearly visible as spherulite boundaries in a polyurethane matrix. Image analysis allows us to conclude that the sizes of the areas resembling spherulite decreases with an introduction of higher amounts of nanofiller. In order to confirm this, quantitative image analysis was performed and sizes of spherulities were calculated. The scheme [13] of the method is presented in 4 
images of polyurethane structure shown in Fig. 4. Measurements were performed for a minimum 100 domains. The results of equivalent diameter analysis of nanocomposite soft domains is shown in Fig. 5 and enumerated in Table 1.

Increasing nanofiller causes decreasing spherulite size.

a)

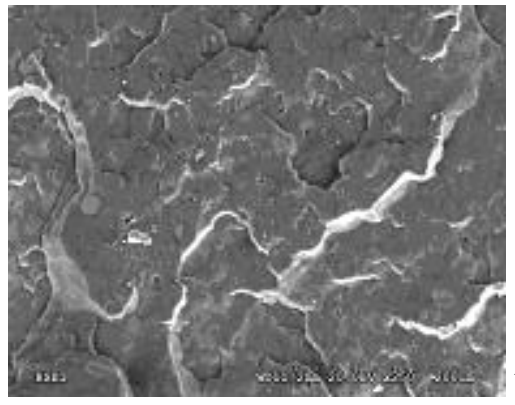

b)

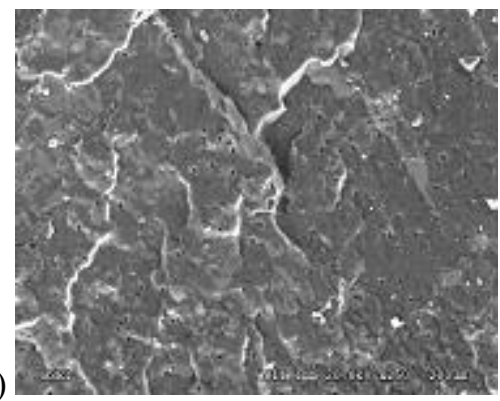

Figure 3: $\quad$ SEM images of cryogenically fractured surfaces of nanocomposites with boehmite: a) $0.5 \mathrm{wt} \%$, b) $3.5 \mathrm{wt} \%$.

Table 1: Equivalent diameter $\left(\mathrm{d}_{2}\right)$ of soft domain the polyurethane and its nanocomposites.

\begin{tabular}{|l|c|c|c|}
\hline Samples & $\begin{array}{l}\text { Average } \mathrm{d}_{2}, \\
{[\mu \mathrm{m}]}\end{array}$ & Max d $_{2}$ & Min d $_{2}$ \\
\hline PUR & $72.9 \pm 37.5$ & 162.7 & 18.4 \\
\hline PUR05 & $24.4 \pm 12.6$ & 108.7 & 1.6 \\
\hline PUR35 & $13.1 \pm 6.9$ & 43.9 & 1.3 \\
\hline
\end{tabular}

Thermal analysis using DSC and TGA was performed; the results are gathered in Fig. 6. On the basis of these results, the glass transition temperature of soft domains ( $\mathrm{Tg}$ ) was specified (tab. 2). We determined that the introduction of the nanofiller does not change the character of the thermogram. Glass point transition temperatures of soft domains of nanocomposite increases slightly. Thermodegradation using TGA was performed; the results are presented in Fig 7 and in table 2. On the basis of the weight variation curves the temperature by 2 and $5 \%$ weight loss $\left(\mathrm{T}_{2 \%}, \mathrm{~T}_{5 \%}\right)$ was specified. Temperature at the maximum for first and second step of weight loss rate read from the peak values of the derivative weigh loss curves (DTG) $\left(\mathrm{T}_{\max 1}\right.$ and $\left.\mathrm{T}_{\max 2}\right)$, see Table 2. Introduction of nanofiller does not influence the change of glass temperature of soft domains. Judging by the gathered results it can be said that the thermal resistance of nanocomposites $\left(\mathrm{T}_{\max 1}\right)$ increases by about $45-50^{\circ} \mathrm{C}$.

Changes were observed in the size of spherulities occurring on the brittle fractures of nanocomposites. The effect of structure on mechanical properties was evaluated for such properties as: hardness $(\mathrm{H})$, tensile at 100 and $300 \%$ elongation $(\sigma 100, \sigma 300)$, tensile strength $(\mathrm{Rm})$, elongation at break $(\varepsilon r)$ and abrasive wear $(\Delta \mathrm{V})$. The results of evaluations are presented in Fig.8. 
a)

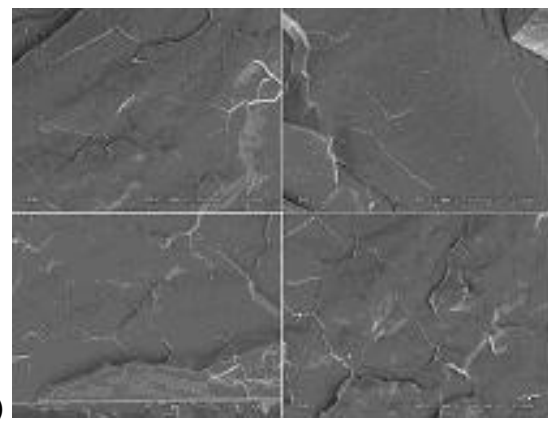

b)

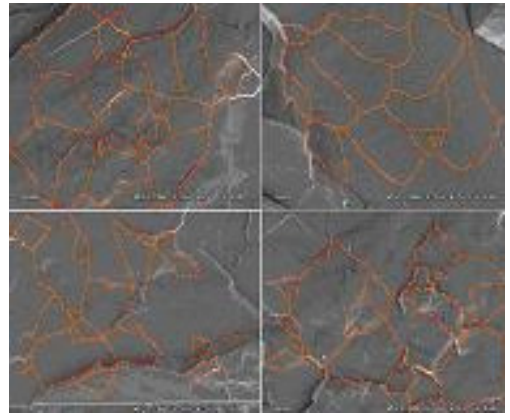

c)
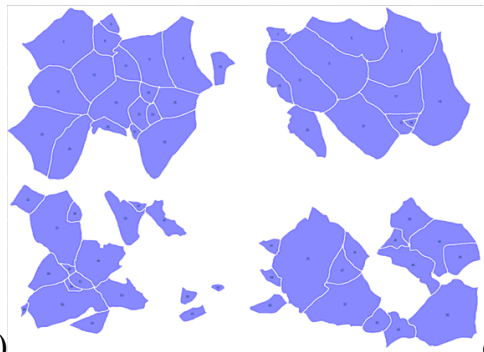

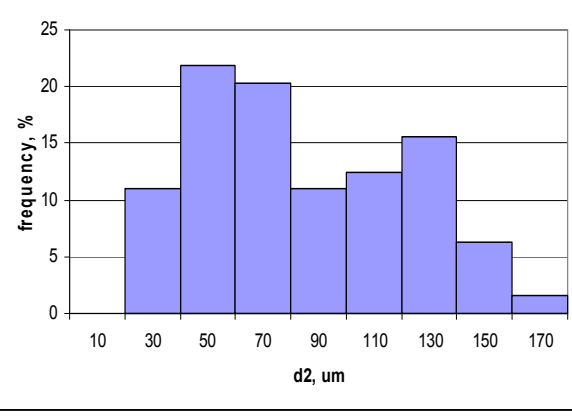

Figure 4: Procedure for soft domain measurement: a) polyurethane microstructure, b) manual object selection, c) image after analysis with use of micrometer program, d) graph showing the distribution of the measurement of equivalent diameter $\left(\mathrm{d}_{2}\right)$ results.

A decrease of spherulities size is connected with a drop in tensile strength and an increase of elongation at break in researched materials. Likewise, decreasing spherulities size is connected with changes in abrasive wear and hardness. Positive changes of abrasive wear after introduction of $0.5 \mathrm{wt} \%$ of modified boehmite are a result of strengthening in the material. Introduction of larger amounts of nanofiller does not influence the change in abrasive wear, which might be connected with pull out whole nanofiller grains.

\section{Conclusion}

Modification using lactic acid causes a change in boehmite structure, which enhances its dispersion in the polyurethane matrix. Introduction of $0.5 \mathrm{wt} \%$ modified boehmite improved the abrasive wear of nanocomposite. Introduction of the nanofiller causes a decrease of resistance properties of researched polyurethanes according to measurements in static tensile tests.

Images of brittle fracture surfaces of researched materials were analysed and prove that an increase in the amount of nanofiller decreases the size of pseudosferolitów occurring on the fracture. A connection has been observed between the decrease of spherulities size and resistance properties specified 
during stretching. Our previous research reported that the introduction of nanofillers into an elastic matrix causes an increase of elasticity modulus and hardness of such composites but a decrease of stretching resistance. Observations obtained during this research help explain the reasons for this phenomenon.

a)
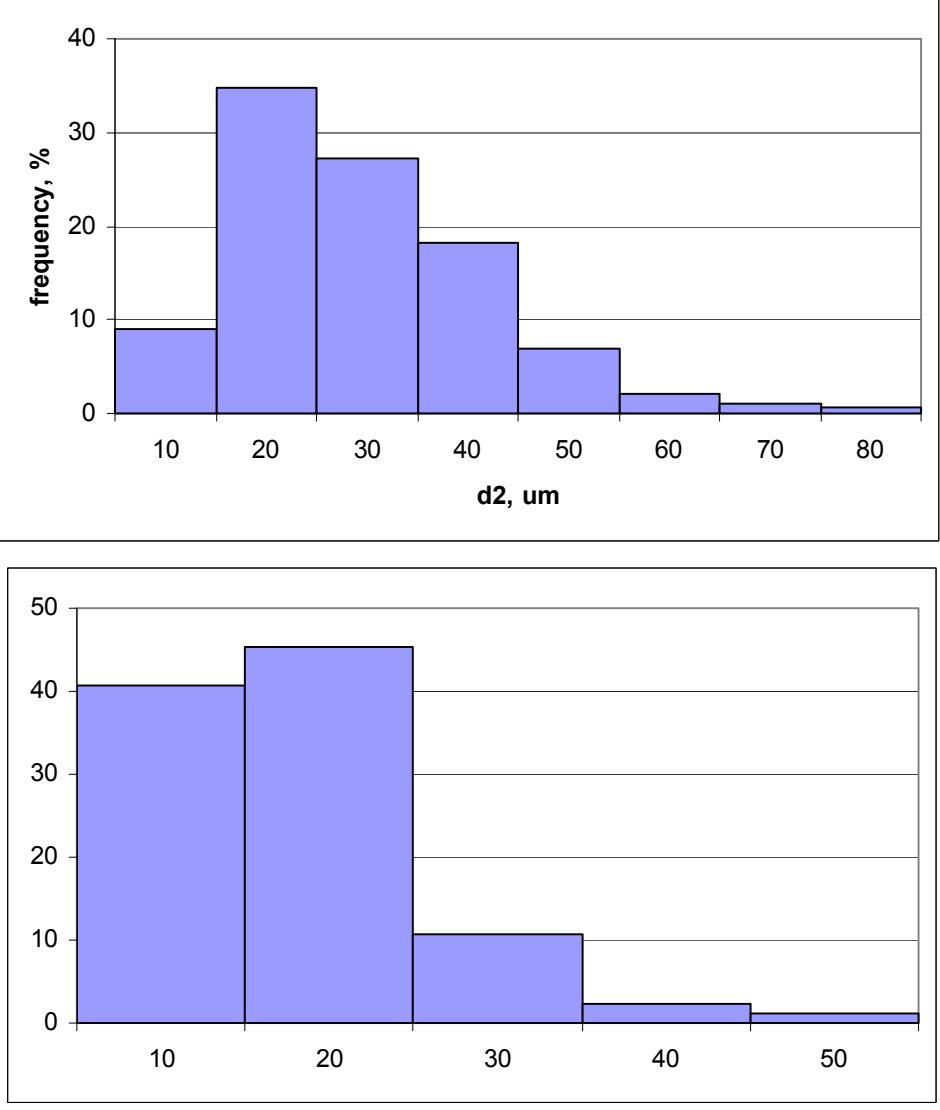

Figure 5: Graph showing the distribution of the measurement of equivalent diameter $(\mathrm{d} 2)$ results.

Table 2: $\quad$ The thermal properties of obtained materials.

\begin{tabular}{|l|c|c|c|c|c|}
\hline Type & $\mathrm{T}_{\mathrm{g} 1}\left({ }^{\circ} \mathrm{C}\right)$ & $\mathrm{T}_{2 \%}\left({ }^{\circ} \mathrm{C}\right)$ & $\mathrm{T}_{5 \%}\left({ }^{\circ} \mathrm{C}\right)$ & $\mathrm{T}_{\max 1}\left({ }^{\circ} \mathrm{C}\right)$ & $\mathrm{T}_{\max 2}\left({ }^{\circ} \mathrm{C}\right)$ \\
\hline PUR & -28.0 & 270.4 & 295.8 & 308.0 & 401.1 \\
\hline PUR05 & -27.8 & 278.0 & 298.9 & 353.6 & 377.9 \\
\hline PUR35 & -27.8 & 278.2 & 297.8 & 362.2 & - \\
\hline
\end{tabular}


Computational Methods and Experiments in Materials Characterisation III 165

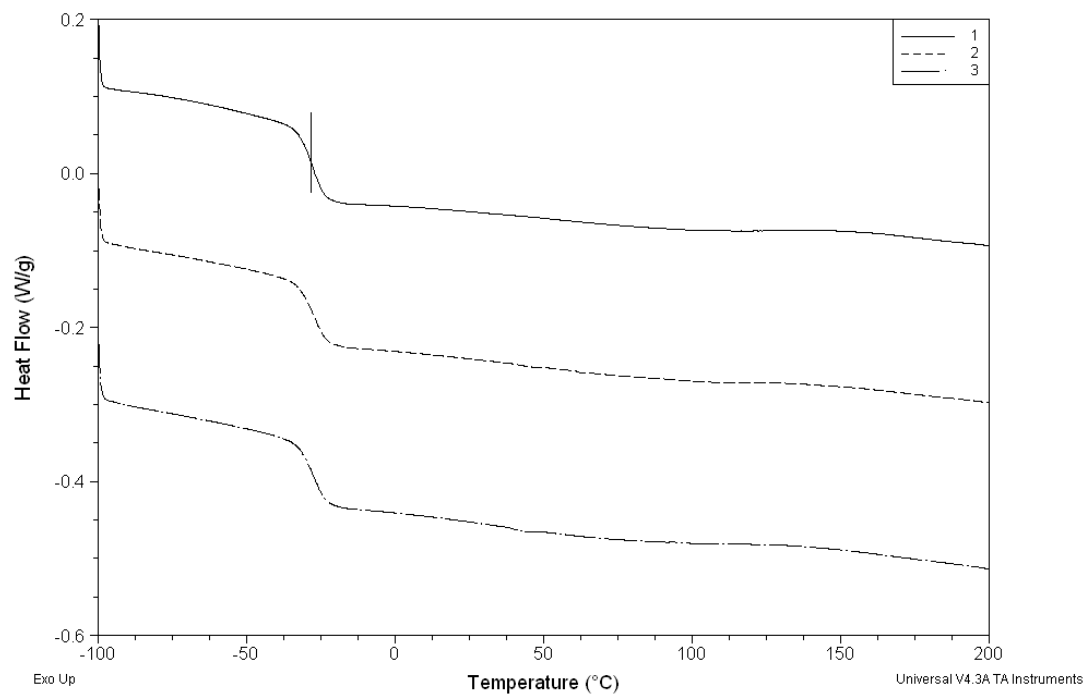

Figure 6: $\quad$ DSC analysis of polyurethane and nanocomposites.

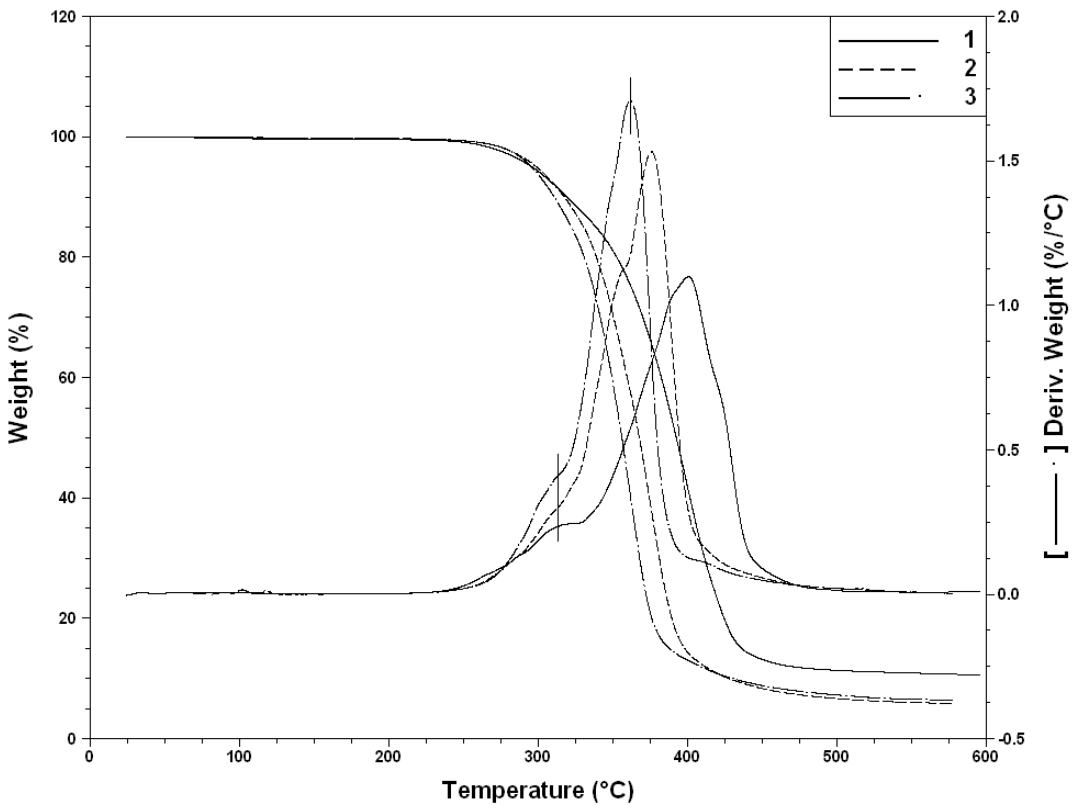

Figure 7: TGA thermograms of polyurethane and nanocomposites. 
166 Computational Methods and Experiments in Materials Characterisation III
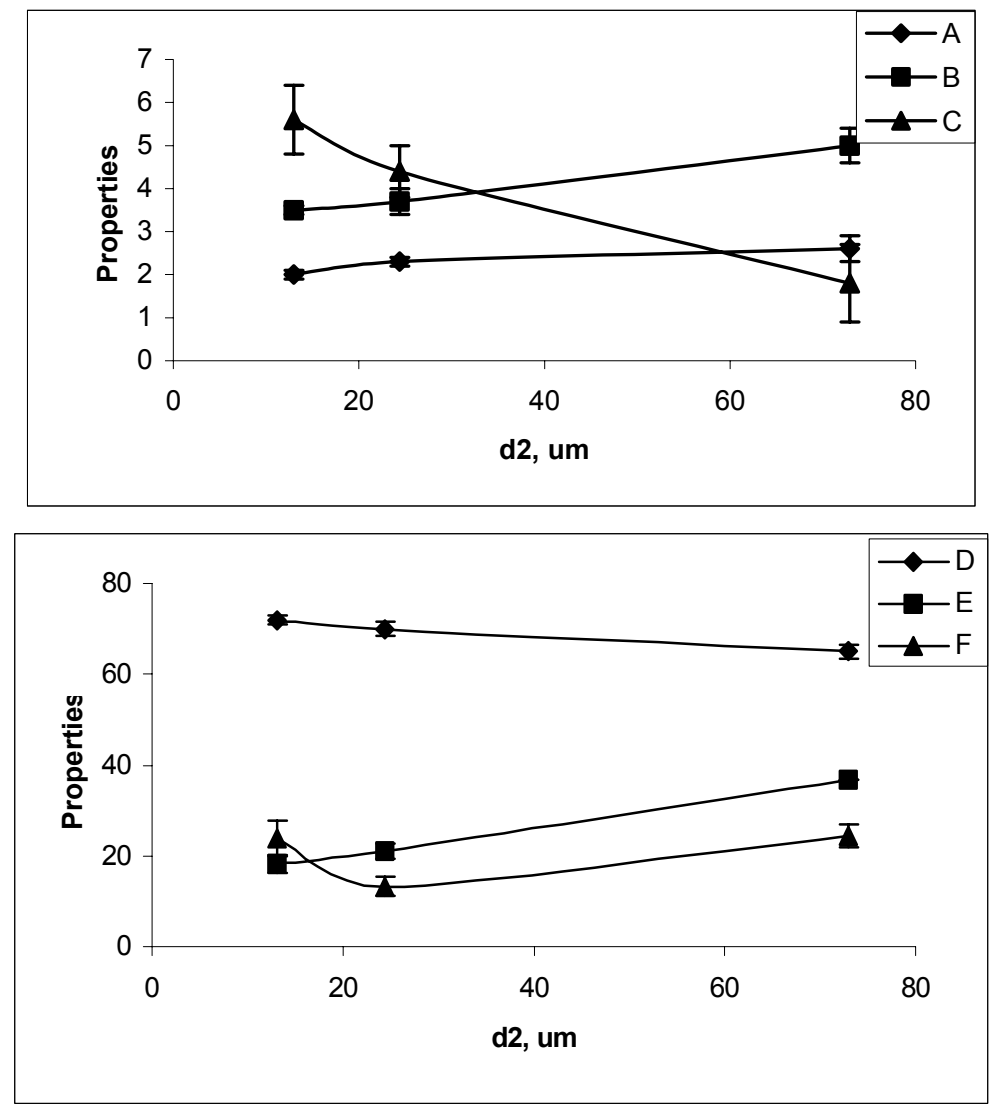

Figure 8: Selected mechanical properties of the polyurethane and nanocomposites as a function of $\mathrm{d} 2$; A, B - tensile at 100 and $300 \%$ elongation $(\sigma 100, \sigma 300), \mathrm{C}$ - elongation at break ( $\varepsilon r), \mathrm{D}-$ hardness $(\mathrm{H}), \mathrm{E}$ - tensile strength $(\mathrm{Rm}), \mathrm{F}$ - abrasive wear $(\Delta \mathrm{V})$.

\section{Acknowledgements}

The author thanks Professor Zbigniew Florjanczyk from Warsaw University of Technology, Faculty of Chemistry for the modified boehmite.

This scientific work was funded from the finances for education in the years 2005-2008 as research project no. 3T08A/07428

\section{References}

[1] Hepburn A. Polyurethane Elastomers, Elsev. Sci. Publ., London, 1992. 
[2] Gruin I, Ryszkowska J, Boczkowska A, Markiewicz B, Zależności właściwości makroskopowych od budowy lanych elastomerów nitrylomocznikowych, Polimery 1994; 39: 226-233.

[3] Gruin et al. Polish patent 148671, 1990.

[4] Gruin et al. Polish patent 150154, 1991.

[5] M.J. Schulz, A. D. Kelkar, M. J. Sundaresan, Nanoengineering of Structural Functional, and Smart Materials, CRC Taylor \&Francis, New York, 2006.

[6] Gogotsi Y., Nanomaterials Handbook, CRC Taylor \&Francis, New York, 2006.

[7] Mai Y. -W., Yu Z.-Z, Polymer nanocomposites, CRC Press, Boca Raton, 2006.

[8] Zheng J., Ozisik R., Siegel R W, Phase separation and mechanical responses of polyurethane nanocomposites, Polymer, 2006, 47, 77867794.

[9] Florjańczyk Z, Rogalska-Jońska E, Nawrocka K, Molenda A, Affek M.: Organoaluminium polymers, Polimery, 2002,47,9, 611- 618.

[10] Foks J, Janik H. Microscopic studies of segmented urethanes with different hard segment content, Polymer Eng. Sci 1989; 29,113-119.

[11] Li Y., Liu J., Yang H, Ma D, Chu B, Multiphase Structure of segmented polyurethanes: Its relation with spherulite structure, J. Polym. Science: Part B Polym. Physics, 1993, 31, 853-867.

[12] Briber R. M., Thomas E.L., Investigation of two crystal forms in MDI/BDO-based polyurethanes, J. Macromol. Sci. - Phys., 1983, B22, 509-528.

[13] Ryszkowska J: Materials Science Forum III, Vols 514-516, (May 2006), p. 1658-1662. 